\title{
əIncorporating Features from the Stochastic Time-Inverted Lagrangian Transport (STILT) Model into the Hybrid Single-Particle Lagrangian Integrated Trajectory (HYSPLIT) Model: A Unified Dispersion Model for Time-Forward and Time-Reversed Applications
}

\author{
Christopher P. Loughner, ${ }^{a}$ Benjamin Fasoli, ${ }^{b}$ Ariel F. Stein, ${ }^{a}$ And John C. Lin ${ }^{b}$ \\ ${ }^{a}$ NOAA/Air Resources Laboratory, College Park, Maryland \\ ${ }^{\mathrm{b}}$ Department of Atmospheric Science, University of Utah, Salt Lake City, Utah
}

(Manuscript received 16 July 2020, in final form 5 April 2021)

\begin{abstract}
The Hybrid Single-Particle Lagrangian Integrated Trajectory model (HYSPLIT) is a state-of-the-science atmospheric dispersion model that is developed and maintained at the National Oceanic Atmospheric Administration's Air Resources Laboratory. In the early 2000s, HYSPLIT served as the starting point for development of the Stochastic TimeInverted Lagrangian Transport (STILT) model that emphasizes backward-in-time dispersion simulations to determine source regions of receptors. STILT continued its separate development and gained a wide user base. Since STILT was built on a now outdated version of HYSPLIT and lacks long-term institutional support to maintain the model, incorporating STILT features into HYSPLIT allows these features to stay up to date. This paper describes the STILT features incorporated into HYSPLIT, which include a new vertical interpolation algorithm for WRF-derived meteorological input files, a detailed algorithm for estimating boundary layer height, a new turbulence parameterization, a vertical Lagrangian time scale that varies in time and space, a complex dispersion algorithm, and two new convection schemes. An evaluation of these new features was performed using tracer release data from the Cross Appalachian Tracer Experiment and the Across North America Tracer Experiment. Results show that the dispersion module from STILT, which takes up to double the amount of time to run, is less dispersive in the vertical direction and is in better agreement with observations when compared with the existing HYSPLIT option. The other new modeling features from STILT were not consistently statistically different than existing HYSPLIT options. Forward-time simulations from the new model were also compared with backward-in-time equivalents and were found to be statistically comparable to one another.
\end{abstract}

KEYWORDS: Dispersion; Lagrangian circulation/transport; Transport; Turbulence; Dispersion; Air pollution

\section{Introduction}

The Hybrid Single-Particle Lagrangian Integrated Trajectory model (HYSPLIT; Stein et al. 2015) is an atmospheric dispersion and trajectory model developed and maintained at the U.S. National Oceanic Atmospheric Administration's (NOAA) Air Resources Laboratory (ARL). The HYSPLIT modeling system contains a broad range of operational and research grade dispersion products (Stein et al. 2015). For instance, HYSPLIT is used operationally by the U.S. National Weather Service Forecast Offices to forecast transport and dispersion of hazardous materials from industrial accidents to protect life and property. In addition, NOAA ARL supports important operational applications using HYSPLIT in the event of nuclear accidents, wildfires, clandestine nuclear activities, and volcanic eruptions. HYSPLIT is also used for quantitative source attribution. By determining the relative importance of different source regions and source types, decision makers can effectively evaluate and prioritize measures that seek to improve human and environmental health and security.

\footnotetext{
¿ Denotes content that is immediately available upon publication as open access.
}

Corresponding author: C. P. Loughner, christopher.loughner@ noaa.gov
The HYSPLIT model has multiple user options to estimate the stability of the atmosphere, calculate velocity variance through a turbulence parameterization, determine mixedlayer depth, and simulate turbulent particle motion (Draxler and Hess 1997). The model can simulate emission, transport, dispersion, deposition, and chemistry within a Lagrangian framework with three dimensional particles by calculating turbulent particle motion directly or as puffs by calculating a statistical distribution (Draxler and Hess 1998). HYSPLIT can also be run within an Eulerian framework or in a mixedmode approach where pollutants are emitted as puffs or particles and then are converted downwind to particles, puffs or onto an Eulerian framework.

The Stochastic Time-Inverted Lagrangian Transport (STILT) model (Lin et al. 2003) is a Lagrangian particle dispersion system used to link receptors with upwind sources. STILT has been widely used to interpret greenhouse gas observations and estimate their emissions (Gerbig et al. 2003; Göckede et al. 2010; McKain et al. 2012; Miller et al. 2013; Lin et al. 2017; Sargent et al. 2018). STILT consists of two parts: 1) an atmospheric dispersion module to simulate particle transport, written in Fortran, and 2) a higher-level module, written in R ( $\mathrm{R}$ Core Team 2020), that manages batches of simulations, provides methods for single and multinode parallelization, and processes the output from the Fortran executable to determine sourcereceptor relationships and estimate emissions (Fasoli et al. 2018).

The atmospheric dispersion component of STILT was built on what is now legacy Fortran code from HYSPLIT in the early 
TABLE 1. A list and brief description of the new HYSPLIT features incorporated from the STILT model.

\begin{tabular}{|c|c|}
\hline New HYSPLIT Feature & Description \\
\hline WRF vertical interpolation & Following same algorithm as in WRF \\
\hline New mixed-layer calculation & $\begin{array}{l}\text { More detailed algorithm that uses excess temperature for convective cases as a } \\
\text { function of virtual potential temperature, } u_{*} \text {, and } w_{*} \text { following Holtslag and } \\
\text { Boville (1993). }\end{array}$ \\
\hline Hanna boundary layer turbulence parameterization & $\begin{array}{l}\text { Computes vertical diffusivity following Hanna (1982) within the PBL and the } \\
\text { standard mixing-length theory above the PBL }\end{array}$ \\
\hline $\begin{array}{l}\text { Lagrangian vertical time scale varying in space } \\
\text { and time }\end{array}$ & $\begin{array}{l}\text { Calculates vertical Lagrangian time scale from the standard deviation of vertical } \\
\text { velocity following Hanna (1982); can be used with all boundary layer } \\
\text { turbulence parameterizations (i.e., not just the Hanna scheme) }\end{array}$ \\
\hline STILT dispersion & $\begin{array}{l}\text { A more complex turbulence module that includes the reflection/transmission } \\
\text { scheme for Gaussian turbulence that preserves well-mixed distributions of } \\
\text { particles moving across interfaces between step changes in turbulence } \\
\text { parameters }\end{array}$ \\
\hline Extreme convection & Extreme convection following Gerbig et al. (2003) \\
\hline Grell convection & Grell scheme utilizing WRF output convective fluxes \\
\hline
\end{tabular}

2000s (Lin et al. 2003). The Fortran code has evolved over time to include additional complex modeling routines for handling pollutant transport via advection, diffusion, and convection. However, STILT lacks sufficient institutional infrastructure and long-term support to maintain and update the Fortran code. Therefore, we have incorporated the additional complex modeling routines for the Fortran component of STILT into HYSPLIT, version 5.0, enabling these STILT routines to be maintained and updated within NOAA ARL. Output from the new merged model is compatible with the STILT model's higher-level R module, which enables STILT users to use the same atmospheric dispersion options in the STILT dispersion module with HYSPLIT. In addition to the traditional STILT functionality, STILT users can also utilize other features of HYSPLIT, which is continually updated and maintained by NOAA ARL.

The next section describes the STILT features that have been incorporated into HYSPLIT. The options from STILT as well as the existing options from HYSPLIT are compared and evaluated with tracer release experiments. The tracer release experiments and the method for evaluation, including the comparisons between the forward-time and backward-time simulations, are described in section 3 . Results and a discussion of the model evaluation is presented in section 4 , and an evaluation of the reversibility of the code is presented in section 5 followed by concluding remarks.

\section{STILT features incorporated into HYSPLIT}

Features within the atmospheric dispersion module of the STILT model have been incorporated into HYSPLIT, version 5.0. These include a new vertical interpolation algorithm for meteorological input files that are derived from WRF Model output, a more detailed algorithm for estimating boundary layer height, a new turbulence parameterization, a vertical Lagrangian time scale that varies in time and space, a more complex dispersion algorithm, and two new convection schemes. These new options are summarized in Table 1 and described in more detail below. The STILT routines have been incorporated into HYSPLIT as user-defined options that can be mixed and matched with existing HYSPLIT options. For example, HYSPLIT can be configured with the STILT dispersion routine and an existing HYSPLIT turbulence parameterization.

\section{a. WRF vertical interpolation scheme}

HYSPLIT can read in multiple different meteorological input files from varying sources and vertical coordinate systems. HYSPLIT interpolates the meteorological variables onto the HYSPLIT vertical coordinate system. A new vertical interpolation scheme has been incorporated into HYSPLIT specifically for meteorological input files that originate from Weather Research and Forecasting (WRF) Model (Skamarock et al. 2008) output files. This scheme mimics the vertical coordinate transformations within the WRF Model by using the same equations within the WRF Model for calculating layer thicknesses, as part of the close coupling implemented between STILT and WRF (Nehrkorn et al. 2010). The vertical coordinate system in WRF is a terrain-following dry hydrostatic pressure-sigma coordinate system and defined as

$$
\sigma=\frac{p_{\mathrm{dh}}-p_{\mathrm{dht}}}{\mu_{d}}, \text { where } \mu_{d}=p_{\mathrm{dhs}}-p_{\mathrm{dht}},
$$

where $\sigma$ is the sigma level and $p_{\mathrm{dh}}, p_{\mathrm{dhs}}$, and $p_{\mathrm{dht}}$ are the dry hydrostatic pressure at the location of interest, surface, and model top, respectively.

The difference between this scheme and the default HYSPLIT scheme for meteorological terrain-following pressure-sigma coordinates is how the schemes estimate the change in height between different vertical levels. In the original HYSPLIT scheme, the change in height $\Delta z$ is calculated using the hypsometric equation:

$$
\Delta z=\frac{\left[\ln \left(P_{\text {bot }}\right)-\ln \left(P_{\text {top }}\right)\right] R_{\mathrm{dry}} 0.5\left(T_{\mathrm{vtop}}+T_{\mathrm{vbot}}\right)}{g},
$$

where $P_{\text {bot }}$ and $P_{\text {top }}$ are the pressure at the bottom and top of the layer, respectively; $R_{\text {dry }}$ is the dry gas constant $\left(287 \mathrm{~J} \mathrm{~K}^{-1} \mathrm{~kg}^{-1}\right)$; 
$T_{\mathrm{vtop}}$ and $T_{\mathrm{vbot}}$ are the virtual temperature at the top and bottom of the layer, respectively; and $g$ is gravity. The new option from STILT estimates $\Delta z$ as (Nehrkorn et al. 2010)

$$
\Delta z=\frac{\mu_{d}\left(\sigma_{\text {top }}-\sigma_{\text {bot }}\right) \alpha_{d}}{g},
$$

where $\mu_{d}$ is the WRF dry mass (dry hydrostatic surface pressure minus the WRF top pressure); $\sigma_{\text {top }}$ and $\sigma_{\text {bot }}$ are the top and bottom sigma levels of the layer, respectively; and $\alpha_{d}$ is the WRF dry inverse density.

\section{b. Mixed-layer depth calculation}

The new method in HYSPLIT to estimate boundary layer depth as adapted from STILT is calculated using a modified Richardson number approach that includes excess temperature for convective cases as a function of virtual potential temperature, friction velocity, and convective vertical velocity following Vogelezang and Holtslag (1996) and summarized here. In this method, mixing height is estimated by a modified bulk Richardson number $R_{i}$ :

$$
R_{i}=\frac{g z\left(\theta_{v}-\theta_{\mathrm{vsc}}\right)}{\theta_{\mathrm{vsc}}\left[\left(u_{z}-u_{s}\right)^{2}+\left(v_{z}-v_{s}\right)^{2}\right]},
$$

where $\theta_{v}$ and $\theta_{\mathrm{vsc}}$ are the virtual potential temperature at height $z$ and excess temperature at the surface due to convection, respectively. Under stable conditions $\theta_{\mathrm{vsc}}=\theta_{\mathrm{vs}}$ (the virtual potential temperature at the surface), and under unstable conditions $\theta_{\mathrm{vsc}}$ includes parcel excess temperature:

$$
\theta_{\mathrm{vsc}}=\theta_{\mathrm{vs}}+\frac{8.5 u_{*} T_{*}\left(\rho_{\mathrm{sl}} / \rho_{z}\right)}{\left(u_{*}^{3}+0.6 w_{*}^{3}\right)^{1 / 3}}
$$

where $\rho_{\mathrm{sl}}$ and $\rho_{z}$ are the density at the top of the surface layer and at height $z$, respectively; $u_{*}$ is the friction velocity; $T_{*}$ is the friction temperature; and $w_{*}$ is the convective velocity scale. The $T_{*}$ and $w_{*}$ are defined as

$$
\begin{aligned}
& T_{*}=-H\left(\rho C_{p} u_{*}\right)^{-1} \text { and } \\
& w_{*}=\left|g u_{*} T_{*} z_{i} T^{-1}\right|^{1 / 3},
\end{aligned}
$$

where $H$ is the sensible heat flux, $C_{p}$ is the heat constant for dry air, and $T$ is temperature. The mixing height is set to height $z$ at which $R_{i}$ is equal to a critical Richardson number $R_{i \text { cr }}$ of 0.25 .

Existing options for mixing-layer depth for use in HYSPLIT include 1) using the mixed-layer depth directly from the meteorological input file, 2) estimating mixed-layer depth with temperature profiles, and 3 ) estimating mixed-layer depth with TKE profiles (Draxler and Hess 1997). HYSPLIT simulations with these three options along with the modified Richardson number approach from STILT will be described in section 4 .

\section{c. Hanna turbulence parameterization}

The Hanna (1982) turbulence parameterization has been incorporated into HYSPLIT. Vertical velocity variances calculated using the Hanna scheme are derived from friction velocity, convective velocity scale, and mixed-layer height. When the Obukhov stability length scale $L$ is greater or less than zero, the vertical velocity variance $w^{\prime 2}$ is defined as

$$
w^{\prime 2}=\left[1.3 u_{*}\left(1-\frac{z}{z_{i}}\right)\right]^{2}
$$

When the Obukhov length scale is less than zero the vertical velocity variance is defined as follows: if $z / z_{i}<0.3$, then

$$
w^{\prime 2}=\left\{0.96 w_{*}\left[\left(3.0 \frac{z}{z_{i}}-\frac{L}{z_{i}}\right)^{1 / 3}\right]\right\}^{2},
$$

if $0.3 \leq z / z_{i}<0.4$, then

$$
w^{\prime 2}=\left\{w_{*} \times \min \left[0.96\left(3.0 \frac{z}{z_{i}}-\frac{L}{z_{i}}\right)^{1 / 3}, 0.763\left(\frac{z}{z_{i}}\right)\right]\right\}^{2},
$$

if $0.4 \leq z / z_{i}<0.96$, then

$$
w^{\prime 2}=\left[0.722 w_{*}\left(1.0-\frac{z}{z_{i}}\right)^{0.207}\right]^{2}
$$

and if $z / z_{i} \geq 0.96$, then

$$
w^{2}=0.37 w_{*}^{2},
$$

where $L$ is the Obukhov length. HYSPLIT does not differentiate between the along-wind and crosswind velocity variances and sets the $u$ and $v$ velocity variances to be the same. When the Hanna scheme is used to calculate vertical velocity variance, horizontal velocity variance is defined as

$$
u^{\prime 2}=v^{\prime 2}=0.5 w^{\prime 2}
$$

HYSPLIT sets the $u$ and $v$ velocity variances to be the same for all existing turbulence parameterizations within the model.

Existing turbulence parameterizations available in HYSPLIT include 1) the Beljaars-Holtslag scheme, 2) the Kantha-Clayson scheme, and 3) a TKE scheme (Draxler and Hess 1997). HYSPLIT simulations with these three simulations and the Hanna turbulence scheme will be compared in section 4 .

\section{d. Hanna vertical Lagrangian time scale}

The Hanna vertical Lagrangian time scale (Hanna 1982) has been incorporated into HYSPLIT. This Lagrangian time scale is calculated using the vertical velocity variances calculated within HYSPLIT's turbulence parameterizations. The Hanna vertical Lagrangian time scale varies in space and time, unlike the standard HYSPLIT vertical Lagrangian time scale that is a user-defined constant. Since all of HYSPLIT's turbulence parameterizations estimate vertical velocity variances, the Hanna vertical Lagrangian time scale can be used with all of HYSPLIT's turbulence parameterizations, not just the Hanna turbulence parameterization. The Hanna vertical Lagrangian time scale $T_{\mathrm{Lw}}$ is defined for stable conditions as

$$
T_{\mathrm{Lw}}=0.1 \frac{z}{w^{\prime}}\left(\frac{z}{z_{i}}\right)^{0.8}
$$


For unstable conditions, $T_{\mathrm{Lw}}$ is defined as

if $\frac{z}{z_{i}}<0.1$ and $z-z_{0}>-L$,

$T_{\mathrm{Lw}}=0.1 \frac{z}{w^{\prime}}\left(0.55+0.38 \frac{z-z_{0}}{L}\right)$,

if $\frac{z}{z_{i}}<0.1 \quad$ and $\quad z-z_{0}<-L, \quad T_{\mathrm{Lw}}=0.59 \frac{z}{w^{\prime}}, \quad$ or

otherwise, $\quad T_{\mathrm{Lw}}=0.15 \frac{z_{i}}{w^{\prime}}\left[1.0-\exp \left(-5 z / z_{i}\right)\right]$,

where $z_{0}$ is the aerodynamic roughness length.

\section{e. STILT dispersion scheme}

The STILT dispersion scheme (Lin et al. 2003; Lin and Gerbig 2012) differs from the standard HYSPLIT dispersion algorithm by utilizing a fractional time step, the Thomson et al. (1997) transmission/reflection scheme and including a very thin model layer above the mixed layer within the dispersion scheme with the goal of preserving a well-mixed distribution of particles and preventing particles from getting trapped just above the mixed layer. Details can be found in Lin and Gerbig (2012) and are summarized below.

A fractional time step is employed where the time step stops and a new one begins every time a particle is transported upward or downward to a model level interface. When a particle reaches an interface between model vertical levels, the Thomson et al. (1997) transmission/reflection scheme is used to preserve a well-mixed distribution of particles across the interface. For an upward-moving particle that reaches a model interface with a vertical turbulent velocity $w_{i}^{\prime}$, it is transmitted with velocity $w_{\text {tup }}^{\prime}$ when the ratio $\alpha_{\text {up }}$ is greater than a random number from a uniform distribution between 0 and 1 and otherwise is reflected from the interface with vertical velocity $-w_{i}^{\prime}$, with

$$
w_{\text {tup }}^{\prime}=w_{i}^{\prime}\left[\frac{\sigma_{w}\left(z_{i+}\right)}{\sigma_{w}\left(z_{i-}\right)}\right] \quad \text { and } \quad \alpha=\left[\frac{\sigma_{w}\left(z_{i+}\right) \rho\left(z_{i+}\right)}{\sigma_{w}\left(z_{i-}\right) \rho\left(z_{i-}\right)}\right] \text {, }
$$

where $\rho$ is density and $z_{i+}$ and $z_{i-}$ represent the interface above and below the current grid cell, respectively. For a downwardmoving particle that reaches a model interface, the particle is transmitted with velocity $w_{\mathrm{tdn}}^{\prime}$ if the ratio $\alpha_{\mathrm{dp}}$ is greater than a random number between 0 and 1 and otherwise is reflected with a velocity $-w_{i}^{\prime}$, where

$$
w_{\text {tup }}^{\prime}=w_{i}^{\prime}\left[\frac{\sigma_{w}\left(z_{i-}\right)}{\sigma_{w}\left(z_{i+}\right)}\right] \quad \text { and } \quad \alpha_{\mathrm{dn}}=\left[\frac{\sigma_{w}\left(z_{i-}\right) \rho\left(z_{i-}\right)}{\sigma_{w}\left(z_{i+}\right) \rho\left(z_{i+}\right)}\right] .
$$

\section{f. Convection}

Two new convection schemes have been adapted from STILT and incorporated into HYSPLIT. The first scheme is an extreme convection method that vertically mixes all particles in grid cells with positive CAPE upward throughout the entire unstable layer defined by the limit of convection (Gerbig et al. 2003). This scheme randomly assigns a vertical position between the surface and the limit of convection altitude $Z_{\mathrm{LOC}}$ to each particle with a vertical position below $Z_{\text {LOC. }}$. The random redistribution is weighted by density. This scheme assumes that updrafts and downdrafts are strong enough within the convection to leave a perfectly well-mixed column behind each convective event. This scheme is designed to provide an upper limit of the impact of subgrid-scale vertical redistribution due to convective cloud transport. A lower limit can be achieved by running HYSPLIT with no convective parameterization.

The second convection scheme incorporated into HYSPLIT is the Grell convection scheme. This scheme ingests convective mass fluxes from the meteorological input files that were generated from WRF Model output files that were run with the Grell et al. (1994) or Grell and Devenyi (2002) convection schemes. These include vertical profiles of updrafts, downdrafts, detrainment, and entrainment fluxes. Vertical profiles of upward and downward vertical velocity are derived from the flux profiles and gridcell fractional coverage of the updrafts and downdrafts. The vertical profiles of the mass fluxes of updrafts, downdrafts, entrainment, and detrainment are used to compute the probability of particles being located within the updrafts, downdrafts, or outside of the convective system.

The existing convection option available in HYSPLIT is based on the extreme convection scheme with a minimum CAPE threshold. When CAPE exceeds a user-defined minimum threshold, then rapid convective mixing is simulated.

\section{HYSPLIT evaluation}

HYSPLIT model simulations run with the new options from the STILT model are evaluated with tracer release observations made during the Cross Appalachian Tracer Experiment (CAPTEX; Ferber et al. 1986) and the Across North American Experiment (ANATEX; Draxler and Heffter 1989). HYSPLIT sampled tracer concentrations on a concentration grid with a horizontal resolution of $0.25^{\circ} \times 0.25^{\circ}$ between the surface and $100 \mathrm{~m}$ above ground level (AGL). Particles were emitted from a height of $10 \mathrm{~m}$. HYSPLIT simulations were run with 50000 particles released for each tracer release cycle and each source. Sensitivity HYSPLIT simulations for the first CAPTEX tracer release experiment with 10 times more particles (500000 particles released) are statistically equivalent (based on the difference in the rank as described below) to simulations with 50000 particles, which shows that 50000 particles are able to simulate statistically robust results. In comparison, Hegarty et al. (2013) performed forward in time HYSPLIT dispersion simulations for CAPTEX with 50000 particles and ANATEX with 25000 particles for each tracer release cycle and each source with the same horizontal and vertical concentration grid resolution as used in this study. Sensitivity simulations performed by Hegarty et al. (2013) reveal little sensitivity in the results as the number of particles increase beyond 25000 . In addition, Hegarty et al. (2013) performed backward STILT dispersion simulations with 500 particles and sensitivity simulations with 5000 particles, which show minimal changes in the results.

CAPTEX took place from mid-September to mid-October 1983 in the northeastern United States and southeastern Canada to investigate the regional transport and diffusion of air pollution. Inert tracers [perfluoromethylcyclohexane $(\mathrm{PMCH}) ; \mathrm{C}_{7} \mathrm{~F}_{14}$ ] were released from Dayton, Ohio, for release experiments 1-4 and 
from Sudbury, Ontario, Canada, for release experiments 5 and 7. A network of ground sampling sites was deployed throughout the northeastern United States and southeastern Canada. Tracer release experiment 6, which was released in Dayton, was not observed in the sampling network and is not used in this study. Tracer releases from Dayton occurred in the afternoon, when the boundary layer was well mixed. Tracer releases at Sudbury occurred after midnight behind cold fronts with northwesterly winds transporting the tracers southeasterly across the sampling network. Observations made during the CAPTEX experiment have been widely used in evaluating atmospheric dispersion models (Stohl et al. 1998; Peltier et al. 2010; Lei et al. 2012; Hegarty et al. 2013; Ngan et al. 2015, 2019; Stein et al. 2015; Forster et al. 2007).

ANATEX took place from early January 1987 to late March 1987 with 33 tracer releases of perfluorotrimethylcyclohexane (PTCH) in Glasgow, Montana, and perfluorodimethylcyclohexane (PDCH) and PMCH in Saint Cloud, Minnesota. Tracers were released in 2.5-day increments to allow for daytime and nighttime releases. Ground sampling sites were deployed throughout the eastern United States and southeastern Canada. In our analysis, we use the PTCH and PDCH data. PMCH was not always released during the nighttime releases. ANATEX observations were used to evaluate dispersion model simulations in past studies (Draxler 2003; Hegarty et al. 2013; Ngan and Stein 2017; Forster et al. 2007). Below, we call the PTCH tracer release experiment from Glasgow ANATEX 1 and the PDCH tracer release experiment from Saint Cloud ANATEX 2.

The HYSPLIT simulations are evaluated using a statistical rank, as described by Draxler (2006). Rank incorporates 1) the square of the linear correlation coefficient $R^{2} ; 2$ ) fractional bias (FB), which defines a normalized measure of bias; 3) figure of merit in space (FMS), which defines the percentage of overlap between measured and predicted areas; and 4) the KolmogorovSmirnov parameter (KS), which defines the maximum difference between two cumulative distributions. These four statistical parameters are normalized to range between 0 and 1 and then summed:

$$
\text { Rank }=R^{2}+\left(1-\left|\frac{\mathrm{FB}}{2}\right|\right)+\frac{\mathrm{FMS}}{100}+\left(1-\frac{\mathrm{KS}}{100}\right) .
$$

Thus, rank ranges from 0 (worst) to 4 (perfect agreement with observations). As described in Stein et al. (2015), two simulations are statistically significantly different if the rank differs by about 0.1 .

In addition to evaluating HYSPLIT simulations with the new STILT options, the existing vertical interpolation, vertical Lagrangian time scale, dispersion, turbulence parameterizations, and convection options are also evaluated to investigate whether statistical differences exist between the various model options. All HYSPLIT model simulations for this study are driven with meteorological input files derived from a 27-km-horizontal-resolution simulation of the WRF Model (Skamarock et al. 2008). These meteorological files are part of an ongoing long-term WRF meteorological archive that began in 1980. Details on the WRF Model configuration for this archive are found in Ngan and Stein (2017).

\section{Evaluation results and discussion}

HYSPLIT simulations were performed for the CAPTEX and ANATEX tracer release experiments, varying the following options: 1) the standard HYSPLIT option of a fixed vertical Lagrangian time scale of $200 \mathrm{~s}$ or the time- and spacevarying Hanna vertical Lagrangian time scale adopted from STILT, 2) the standard HYSPLIT vertical interpolation scheme or the WRF vertical interpolation algorithm from STILT, and 3) the standard HYSPLIT dispersion algorithm or the more complex STILT dispersion scheme.

Figure 1 shows the statistical rank of HYSPLIT simulations varying the above three options. All simulations calculated boundary layer stability using wind and temperature profiles, the Kantha-Clayson turbulence parameterization, average wind fields, and no convection. Shown in Fig. 1, changing the vertical interpolation or the vertical Lagrangian time scale schemes result in a rank that differs by less than 0.1 for all of the CAPTEX and ANATEX 1 tracer release experiments, which is statistically insignificant as described by Stein et al. (2015). However, the improved model performance with the more complex STILT dispersion scheme (Lin and Gerbig 2012) as compared with the simulations with the HYSPLIT dispersion scheme is statistically significant for CAPTEX and ANATEX 1. The STILT dispersion scheme results in an increase in rank between 0.08 and 0.18 for CAPTEX and between 0.23 and 0.34 for ANATEX 1 (Table 2). The STILT dispersion scheme is more complex (Lin and Gerbig 2012), requiring more computational resources. HYSPLIT simulations with the STILT dispersion scheme took up to double the amount of time to run than a simulation with the existing HYSPLIT dispersion scheme.

However, the STILT dispersion scheme did not improve results for ANATEX 2. The rank for the HYSPLIT simulations with the STILT dispersion scheme were lower, but not statistically significantly different than simulations with the standard HYSPLIT dispersion scheme (Fig. 1 and Table 2). There were frequent large model biases at two measurement locations during nighttime releases. These measurement locations were 31 and $86 \mathrm{~km}$ from the tracer release location. The plume may have stayed aloft and may not have mixed down to the surface by the time the plume was transported over these two measurement locations, resulting in the high model biases at these sites. The statistics for ANATEX 2 were recalculated without measurements included for these two sites and are called ANATEX $2 b$ for the remainder of this paper. Figure 1 and Table 2 shows that HYSPLIT simulations with the STILT dispersion scheme outperforms the HYSPLIT dispersion scheme for ANATEX 2b, with an increase in the rank between 0.19 and 0.35 .

Tracer concentrations between the surface and $100 \mathrm{~m}$ AGL from eight HYSPLIT simulations of CAPTEX are shown in Fig. 2. Concentrations are higher for all simulations that utilize the STILT dispersion algorithm than the corresponding simulation that uses the HYSPLIT dispersion algorithm. This pattern is consistent for all of the tracer release experiments. Table 3 shows the mean bias of HYSPLIT simulations. The average mean bias of the CAPTEX simulations decreased from $-61 \mathrm{pg} \mathrm{m}^{-3}$ for the HYSPLIT dispersion scheme to $-15 \mathrm{pg} \mathrm{m}^{-3}$ for the STILT dispersion scheme. 


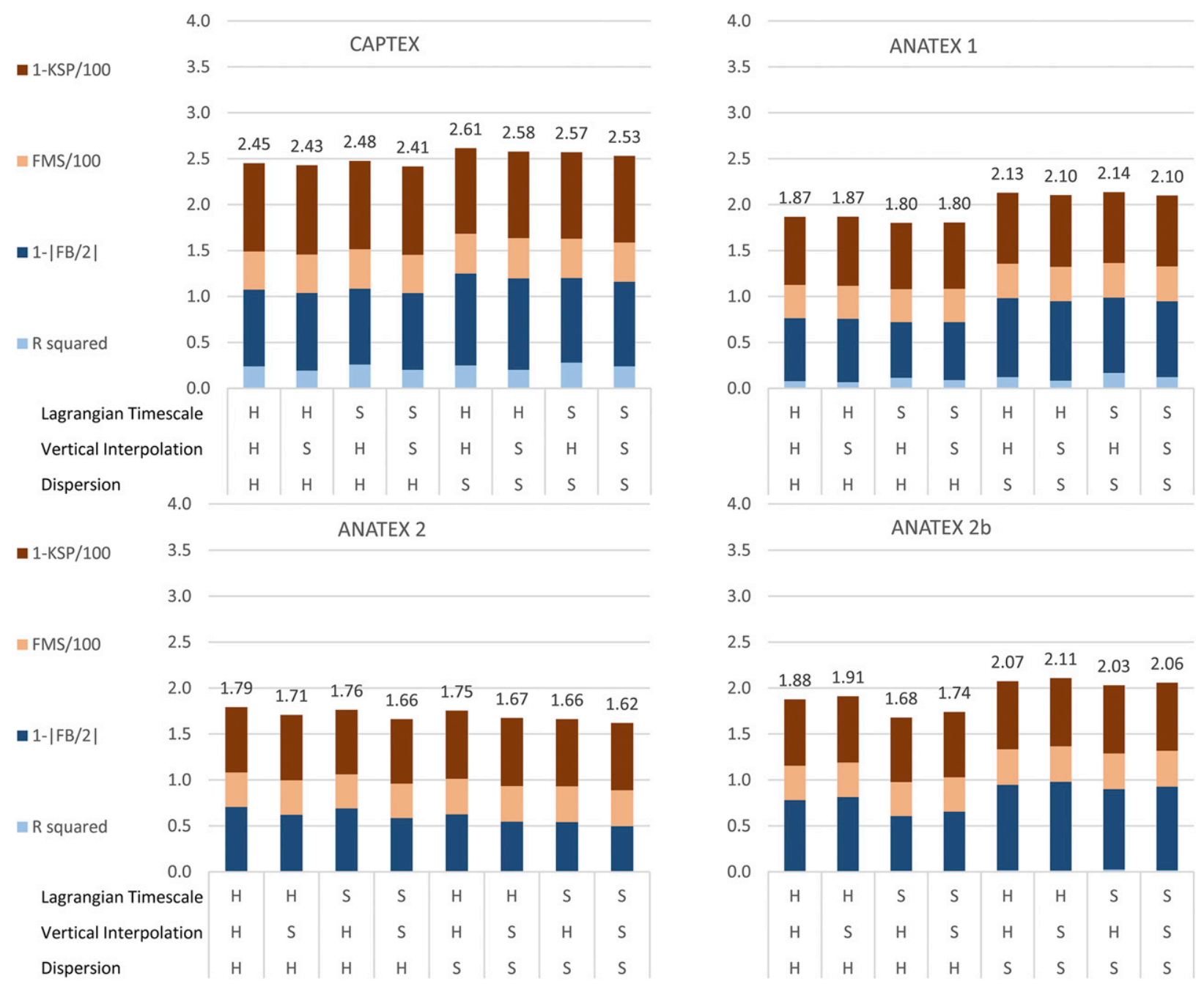

FIG. 1. Rank (numbers above bars) and the statistical measures that derive rank (colored bars) for CAPTEX, ANATEX 1, ANATEX 2, and ANATEX 2b HYSPLIT simulations with varying vertical interpolation, vertical Lagrangian time scale, and dispersion schemes between the standard HYSPLIT (H) options and the new options adopted from STILT (S). All simulations use the boundary layer depth from the meteorological input file, calculate boundary layer stability from temperature and relative humidity profiles, and use the KanthaClayson turbulence parameterization and no convection.

Similarly, the negative biases with the HYSPLIT dispersion scheme for ANATEX 1 and ANATEX $2 b$ decreased in magnitude with the STILT dispersion scheme. The increase in tracer concentrations in the STILT scheme is due to the inclusion of the Thomson transmission/reflection scheme. As described above, when a particle is transported upward or downward to a model level interface within the STILT dispersion scheme, the particle will either be transmitted or reflected based on the ratio $\alpha_{\text {up }}$ [Eq. (18)] or $\alpha_{\text {dn }}$ [Eq. (19)] and a random number between 0 and 1 . For the HYSPLIT dispersion scheme, the particles that reach the model interface are always transmitted (except when they reach the ground or model top). This results in the HYSPLIT dispersion scheme being more dispersive, with more transport between the boundary layer and free troposphere in the vertical than the STILT dispersion option. An increase in boundary layer venting resulted in lower surface concentrations with the HYSPLIT dispersion scheme than the STILT scheme for CAPTEX and ANATEX where tracers were released in the boundary layer at $10 \mathrm{~m}$ AGL.

Additional HYSPLIT simulations were performed to evaluate the Hanna turbulence parameterization, in comparison with three existing HYSPLIT turbulence options: the BeljaarsHoltslag, Kantha-Clayson, and TKE schemes. Four HYSPLIT simulations were simulated for the CAPTEX and ANATEX tracer release experiments with different turbulence parameterizations. All simulations are performed with no convection, use the boundary layer depth from the meteorological input file, calculate boundary layer stability from temperature and relative humidity profiles, and utilize the new options from STILT for vertical interpolation, vertical Lagrangian time scale, and dispersion. Results do not reveal that one turbulence parameterization provides consistent statistically significant 
TABLE 2. Rank of HYSPLIT simulations covering all CAPTEX experiments with varying vertical interpolation, vertical Lagrangian time scale, and dispersion schemes between the standard HYSPLIT options and the new options adopted from STILT. All simulations use the boundary layer depth from the meteorological input file, calculate boundary layer stability from temperature and relative humidity profiles, and use the Kantha-Clayson turbulence parameterization and no convection.

\begin{tabular}{|c|c|c|c|c|c|}
\hline & $\begin{array}{l}\text { Vertical interpolation } \\
\text { Lagrangian time scale }\end{array}$ & $\begin{array}{l}\text { HYSPLIT } \\
\text { HYSPLIT }\end{array}$ & $\begin{array}{c}\text { STILT } \\
\text { HYSPLIT }\end{array}$ & $\begin{array}{l}\text { HYSPLIT } \\
\text { STILT }\end{array}$ & $\begin{array}{l}\text { STILT } \\
\text { STILT }\end{array}$ \\
\hline CAPTEX & HYSPLIT dispersion & 2.45 & 2.43 & 2.48 & 2.41 \\
\hline CAPTEX & STILT dispersion & 2.61 & 2.58 & 2.57 & 2.53 \\
\hline ANATEX 1 & HYSPLIT dispersion & 1.87 & 1.87 & 1.80 & 1.80 \\
\hline ANATEX 1 & STILT dispersion & 2.13 & 2.10 & 2.14 & 2.10 \\
\hline ANATEX 2 & HYSPLIT dispersion & 1.79 & 1.71 & 1.76 & 1.66 \\
\hline ANATEX 2 & STILT dispersion & 1.75 & 1.67 & 1.66 & 1.62 \\
\hline ANATEX $2 b$ & HYSPLIT dispersion & 1.88 & 1.91 & 1.68 & 1.74 \\
\hline ANATEX $2 b$ & STILT dispersion & 2.07 & 2.11 & 2.03 & 2.06 \\
\hline
\end{tabular}

improvements (Fig. 3). The Beljaars-Holtslag, Kantha-Clayson, and STILT schemes outperform the TKE scheme for CAPTEX, Beljaars-Holtslag and STILT schemes perform best for ANATEX 1, and all schemes show statistically similar results for ANATEX 2b.

A similar set of HYSPLIT simulations was performed for testing the STILT algorithm for estimated mixed-layer depth alongside the existing HYSPLIT options, which include using the boundary layer depth input from the meteorological input files, calculating the mixed-layer depth from the temperature profile, and calculating the mixedlayer depth from the TKE profile. This set of simulations was performed with no convection, boundary layer stability from temperature and relative humidity profiles, the KanthaClayson turbulence parameterization, and the new options from STILT for vertical interpolation, vertical Lagrangian time scale, and dispersion. Similarly, there is no single option for calculating the mixed-layer depth that statistically outperforms the other options on a consistent basis (Fig. 4).

The two new convection schemes imported from STILT, the Grell and extreme schemes, are evaluated during the CAPTEX and ANATEX tracer release experiments alongside simulations with no convection and the HYSPLIT option of rapid mixing if CAPE exceeds a threshold, which was set to $500 \mathrm{~J} \mathrm{~kg}^{-1}$. All of these convection sensitivity experiments were performed with HYSPLIT using the mixed-layer
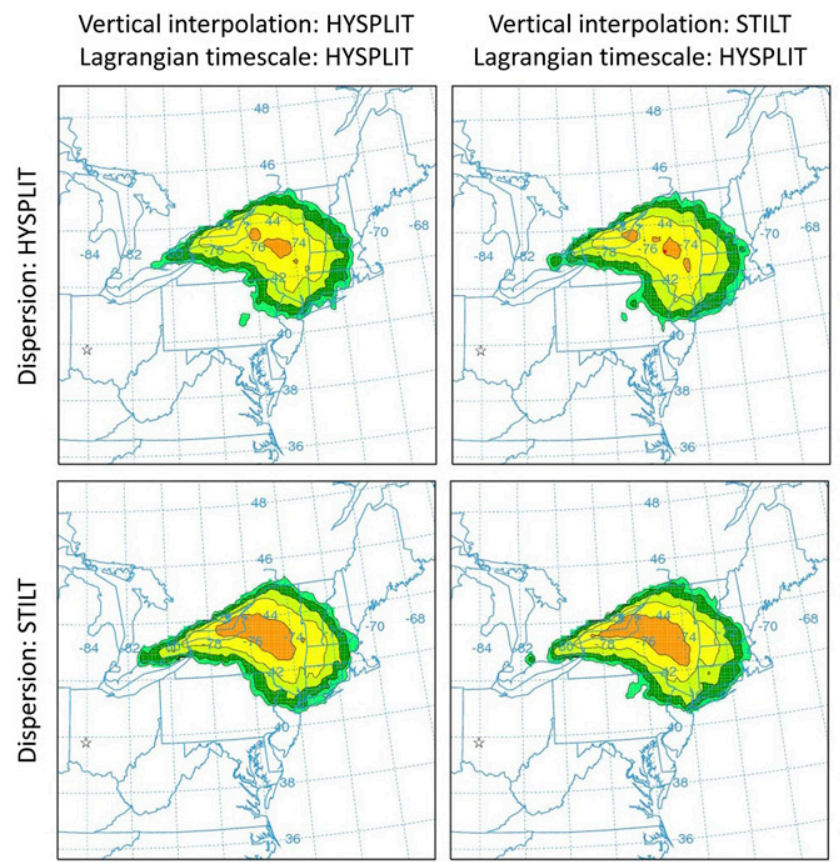

Vertical interpolation: HYSPLIT Lagrangian timescale: STILT
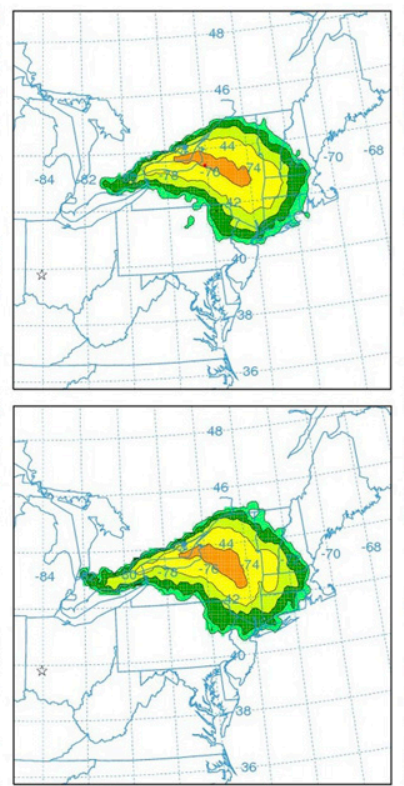

Vertical interpolation: STILT Lagrangian timescale: STILT
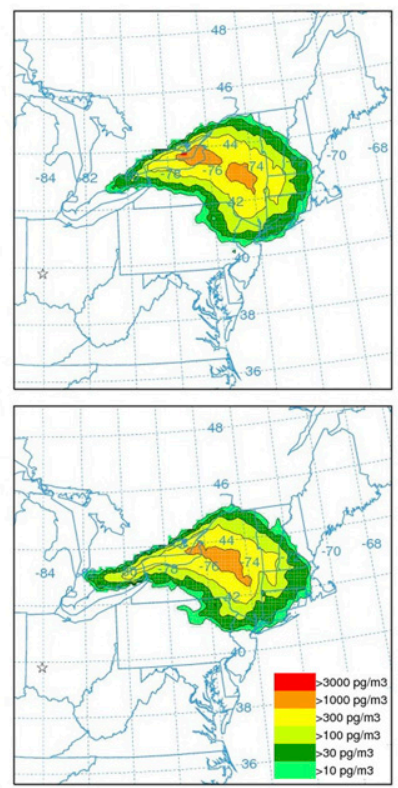

FIG. 2. Average surface-to-100 m AGL tracer concentrations between 0900 and 1200 UTC 19 Sep 1983 of eight HYSPLIT simulations (contours) during CAPTEX. Eight HYSPLIT simulations are shown with varying vertical interpolation, vertical Lagrangian time scale, and dispersion schemes between the standard HYSPLIT options and the new options adopted from STILT. All simulations use the boundary layer depth from the meteorological input file, calculate boundary layer stability from temperature and relative humidity profiles, and use the Kantha-Clayson turbulence parameterization and no convection. 
TABLE 3. Mean bias of HYSPLIT simulations varying the vertical interpolation, vertical Lagrangian time scale, and dispersion schemes between the standard HYSPLIT options and the new options adopted from STILT. All simulations use the boundary layer depth from the meteorological input file, calculate boundary layer stability from temperature and relative humidity profiles, and use the Kantha-Clayson turbulence parameterization and no convection.

\begin{tabular}{|c|c|c|c|c|c|}
\hline & $\begin{array}{l}\text { Vertical interpolation } \\
\text { Lagrangian time scale }\end{array}$ & $\begin{array}{l}\text { HYSPLIT } \\
\text { HYSPLIT }\end{array}$ & $\begin{array}{c}\text { STILT } \\
\text { HYSPLIT }\end{array}$ & $\begin{array}{l}\text { HYSPLIT } \\
\text { STILT }\end{array}$ & $\begin{array}{l}\text { STILT } \\
\text { STILT }\end{array}$ \\
\hline CAPTEX & HYSPLIT dispersion & -61.45 & -58.33 & -63.98 & -61.28 \\
\hline CAPTEX & STILT dispersion & 0.39 & 1.12 & -32.13 & -31.17 \\
\hline ANATEX 1 & HYSPLIT dispersion & -6.75 & -6.65 & -7.92 & -7.57 \\
\hline ANATEX 1 & STILT dispersion & -3.46 & -3.30 & -4.30 & -4.21 \\
\hline ANATEX 2 & HYSPLIT dispersion & 8.35 & 12.45 & 9.13 & 14.21 \\
\hline ANATEX 2 & STILT dispersion & 12.12 & 16.87 & 17.33 & 20.70 \\
\hline ANATEX $2 b$ & HYSPLIT dispersion & -3.52 & -3.08 & -5.36 & -4.78 \\
\hline ANATEX 2b & STILT dispersion & -1.26 & -0.59 & -2.1 & -1.54 \\
\hline
\end{tabular}

height from the meteorological input files, boundary layer stability calculated from temperature and relative humidity profiles, the Kantha-Clayson turbulence parameterization, and the new options from STILT for vertical interpolation, vertical Lagrangian time scale, and dispersion. Results show that the simulations with no convection, Grell convection, and CAPE threshold of $500 \mathrm{~J} \mathrm{~kg}^{-1}$ produce similar results (Fig. 5). The extreme convection simulation underperformed as compared with the other three convective options for CAPTEX, ANATEX 1, and ANATEX 2b (Fig. 5). The no convection, Grell convection, and CAPE threshold options are expected to produce similar results in a nonconvective atmosphere where simulated Grell convective fluxes are small and CAPE is less than $500 \mathrm{~J} \mathrm{~kg}^{-1}$. However, if CAPE is positive, rapid convective mixing will take place with the extreme convection scheme. For example, the extreme convection case during the fifth tracer release experiment of CAPTEX simulated significantly lower concentrations near the surface as compared with the other three model configurations due to rapid convective mixing (Fig. 6). However, the extreme convection scheme is not meant to be used as a standalone simulation. The extreme convection scheme was generated to produce an upper bound of how rapid pollutants can mix due to convection. This scheme should be used alongside a simulation with convection turned off as a

\section{0}

\section{5}

3.0

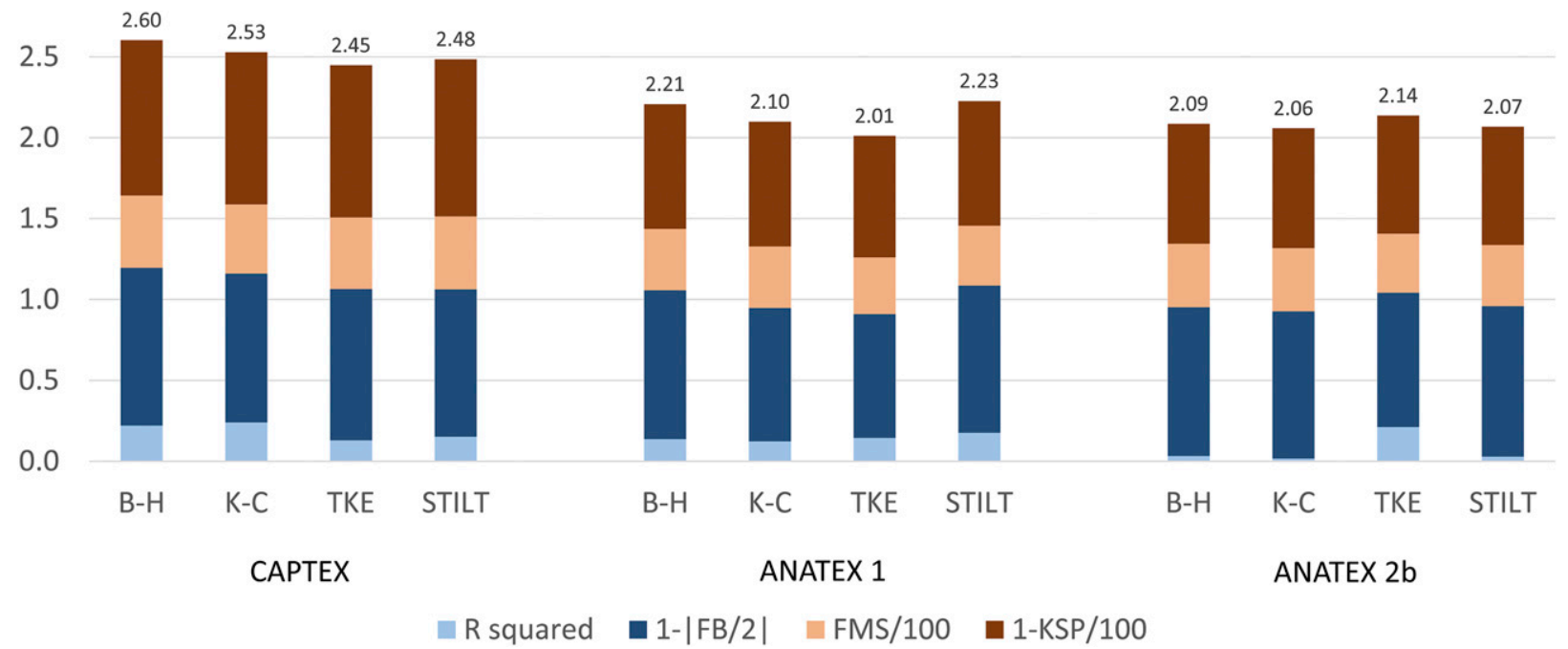

FIG. 3. Rank (numbers above bars) and the statistical measures that derive rank (colored bars) for HYSPLIT simulations of CAPTEX, ANATEX 1, and ANATEX 2b with varying turbulence parameterizations [Beljaars-Holtslag (B-H); Kantha-Clayson (K-C); TKE; Hanna (STILT)]. All simulations use the boundary layer depth from the meteorological input file, calculate boundary layer stability from temperature and relative humidity profiles, have no convection, and use the new options from STILT for vertical interpolation, Lagrangian time scale, and dispersion. 


\section{0}

3.5

3.0

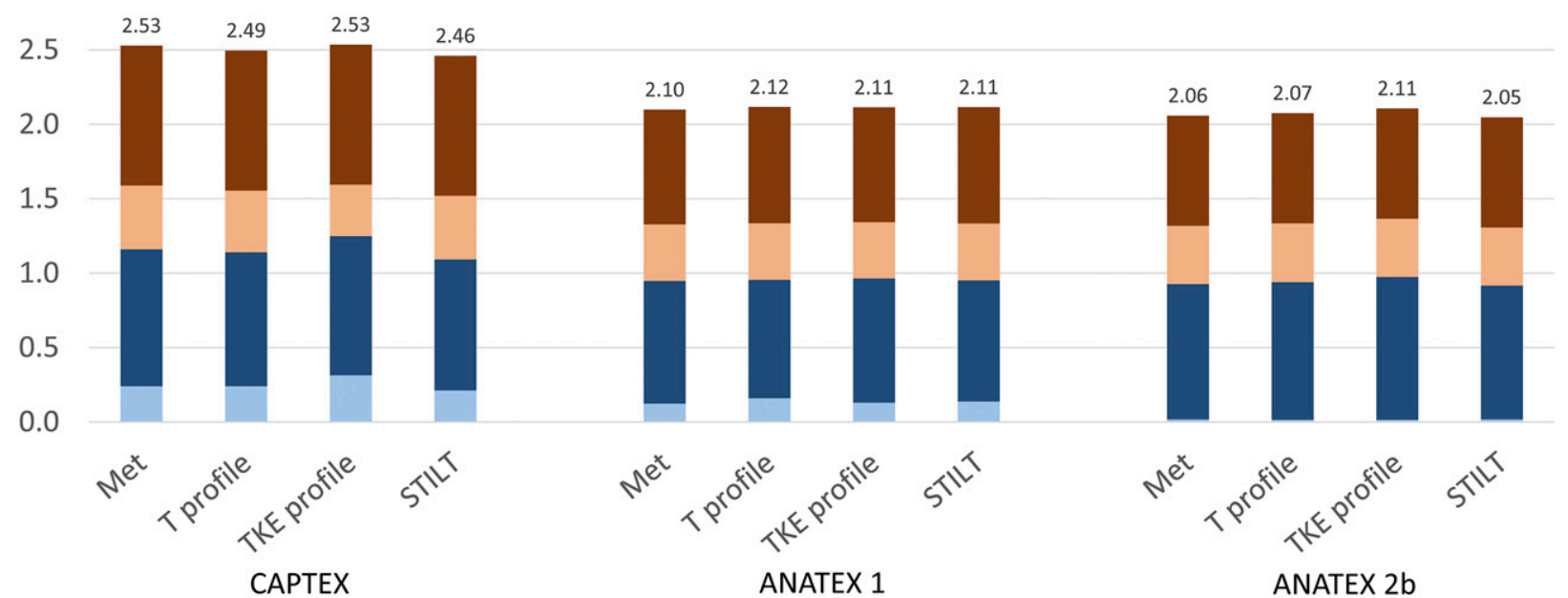

$\square$ R squared $\square 1-|F B / 2| \quad$ FMS/100 $\square$ 1-KSP/100

FIG. 4. Rank (numbers above bars) and the statistical measures that derive rank (colored bars) for HYSPLIT simulations of CAPTEX, ANATEX 1, and ANATEX 2b with varying options for estimating the mixed-layer depth [directly from the meteorological input file (Met); calculated from the temperature profile (T profile); calculated from the TKE profile (TKE profile); new option from STILT (STILT)]. All simulations use the Kantha-Clayson turbulence parameterization, calculate boundary layer stability from temperature and relative humidity profiles, and use the new options from STILT for vertical interpolation, Lagrangian time scale, and dispersion.

lower bound to convective mixing. Therefore, it is not surprising that the extreme convection case simulates a low bias in surface concentrations due to excessive convective mixing. Future work evaluating the different convective parameterizations within HYSPLIT during convective scenarios would be beneficial.

\section{Time reversibility}

The STILT model is primarily used to follow air parcels backward in time, which identifies the upstream source region influencing the tracer concentration at a receptor. We evaluated the updated model's ability to reproduce forward in time simulations initialized at the CAPTEX tracer release locations using backward in time simulations initialized at the CAPTEX measurement locations.

When running HYSPLIT in STILT mode, the mass summation of particles is divided by density to output a mixing ratio, the lowest concentration summation layer is optionally permitted to vary with mixing-layer depth, and text files of particle position information are output. HYSPLIT was run with the STILT dispersion, WRF vertical interpolation, Hanna turbulence and Lagrangian time scale, no convection, boundary layer stability estimated from heat and momentum fluxes, and mixed-layer depth calculated with the new STILT scheme utilizing a modified Richardson number. Running HYSPLIT in STILT mode backward in time calculates a "footprint" field that represents the sensitivity of a receptor to upwind sources
(Lin et al. 2003). For the CAPTEX experiments, the computational expense of running multiple backward simulations was significantly greater than using a single forward simulation, since the number of sources from which the tracer was released was small relative to the number of receptors. However, conversely, backward simulations can yield significant computational savings when potential sources outnumber receptors.

Receptors corresponding with the locations and times of measurements were used to initialize each simulation. For both the backward and forward simulations, we used an ensemble with 50000 particles averaged over a $0.25^{\circ} \times 0.25^{\circ}$ grid from the surface to $100 \mathrm{~m}$ AGL. The backward footprints estimate each receptor's sensitivity to emissions originating from elsewhere within the model domain. Convolving the footprints with the known $\mathrm{PMCH}$ emission rate at the release location estimates the contribution of the tracer release to the observed mixing ratio.

The results show that the backward model has similar performance characteristics to the forward model (Table 4). The forward and backward HYSPLIT simulations produced similar PMCH concentrations at each measurement location $\left(R^{2}=0.88\right)$. These results agree with prior literature, in which backward simulations were able to recover most of the variance explained by forward simulations (Lin et al. 2003). Differences in the modelobservation errors between the forward and backward approaches were found to be statistically insignificant within the 


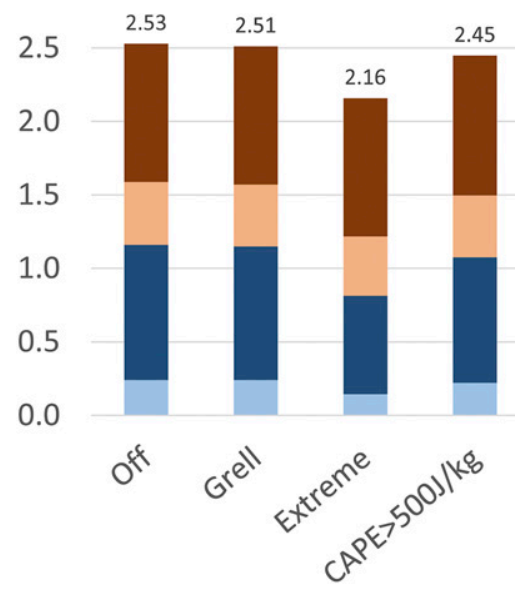

CAPTEX
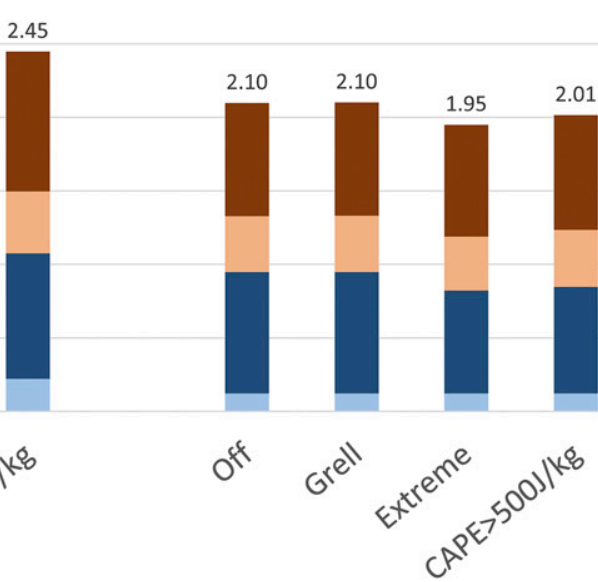

ANATEX 1
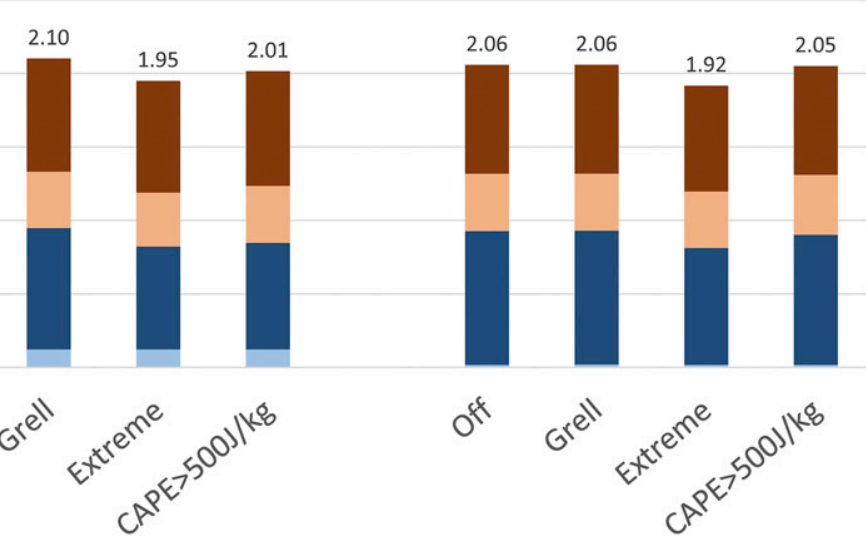

ANATEX $2 b$

\section{n squared $\square 1-|F B / 2|=F M S / 100$ - $1-\mathrm{KSP} / 100$}

FIG. 5. Rank (numbers above bars) and the statistical measures that derive rank (colored bars) for HYSPLIT simulations of CAPTEX, ANATEX 1, and ANATEX 2b with varying convection options [convection turned off (Off); the Grell convective scheme from STILT (Grell); extreme convection from STILT (Extreme); and a CAPE threshold of $500 \mathrm{~J} \mathrm{~kg}^{-1}$ (CAPE $>500 \mathrm{~J} / \mathrm{kg}$ )]. All simulations use the boundary layer depth from the meteorological input file, use the Kantha-Clayson turbulence parameterization, calculate boundary layer stability from temperature and relative humidity profiles, and use the new options from STILT for vertical interpolation, Lagrangian time scale, and dispersion.

$95 \%$ confidence interval (mean model error of $-34.45 \mathrm{pg} \mathrm{m}^{-3}$ for forward simulation and $-34.89 \mathrm{pg} \mathrm{m}^{-3}$ for backward simulation).

\section{Conclusions}

Since the atmospheric dispersion module of STILT is built on an outdated version of HYSPLIT, the incorporation of STILT features into HYSPLIT, version 5.0, allows for these routines to stay up to date. HYSPLIT is continually updated and maintained at NOAA ARL. The new features in HYSPLIT incorporated from STILT include a new vertical interpolation algorithm for meteorological input files that are derived from WRF Model output, a more detailed algorithm for estimating boundary layer height, a new turbulence parameterization, a vertical Lagrangian
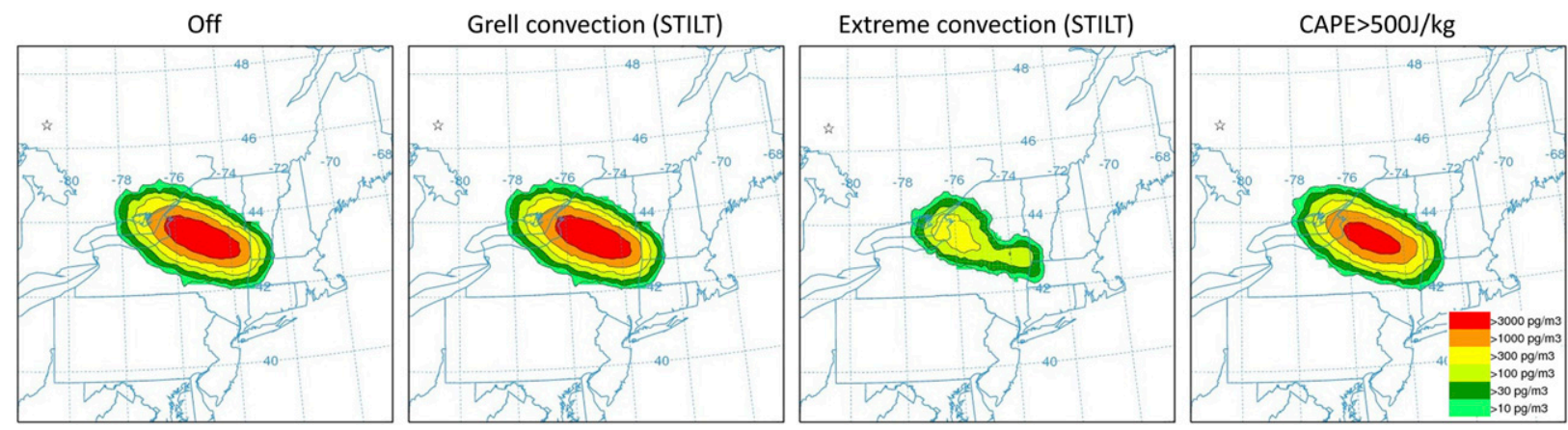

FIG. 6. Average surface-to-100 m AGL tracer concentrations between 2100 UTC 26 Oct 1983 and 0000 UTC 27 Oct 1983 of four HYSPLIT simulations (contours) and observed surface concentrations (numbers) during the fifth tracer release of CAPTEX. Four HYSPLIT simulations are shown with varying vertical interpolation: convection turned off, the Grell convection scheme from STILT, the extreme convection scheme from STILT, and the scheme with a CAPE threshold of $500 \mathrm{~J} \mathrm{~kg}^{-1}$. All simulations use the boundary layer depth from the meteorological input file, use the Kantha-Clayson turbulence parameterization, calculate boundary layer stability from temperature and relative humidity profiles, and use the new options from STILT for vertical interpolation, Lagrangian time scale, and dispersion. 
TABLE 4. The $R^{2}$ values for six individual CAPTEX tracer release experiments between backward HYSPLIT simulated and observed concentrations, forward HYSPLIT simulated and observed concentrations, and backward and forward HYSPLIT simulated concentrations. Uncertainties are determined by randomly sampling the observed and modeled distributions with replacement (bootstrapping) and are expressed as the standard deviation of $R^{2}$ values derived from the resampled distributions $(n=1000)$.

\begin{tabular}{|c|c|c|c|}
\hline & $R^{2}$ (backward HYSPLIT - obs) & $R^{2}$ (forward HYSPLIT - obs) & $\begin{array}{l}R^{2} \text { (backward HYSPLIT - } \\
\text { forward HYSPLIT) }\end{array}$ \\
\hline CAPTEX 1 & $0.45 \pm 0.19$ & $0.60 \pm 0.15$ & $0.95 \pm 0.04$ \\
\hline CAPTEX 2 & $0.05 \pm 0.1$ & $0.12 \pm 0.13$ & $0.77 \pm 0.07$ \\
\hline CAPTEX 3 & $0.51 \pm 0.31$ & $0.53 \pm 0.3$ & $0.99 \pm 0.06$ \\
\hline CAPTEX 4 & $0.01 \pm 0.04$ & $0.14 \pm 0.15$ & $0.85 \pm 0.14$ \\
\hline CAPTEX 5 & $0.63 \pm 0.15$ & $0.60 \pm 0.18$ & $0.94 \pm 0.02$ \\
\hline CAPTEX 7 & $0.05 \pm 0.08$ & $0.03 \pm 0.03$ & $0.99 \pm 0.02$ \\
\hline
\end{tabular}

time scale that varies in time and space, a more complex dispersion algorithm, and two new convection schemes.

An evaluation of these new options alongside existing HYSPLIT options using a long-term 27-km-horizontal-resolution WRF meteorological archive (Ngan and Stein 2017) for the CAPTEX and ANATEX tracer release experiments reveals that the new dispersion scheme from STILT agrees better than simulations with the HYSPLIT dispersion module. However, the STILT dispersion scheme does require more computational resources. The STILT dispersion scheme is less dispersive in the vertical than the HYSPLIT scheme due to the inclusion of the Thomson reflection/transmission scheme resulting in less boundary layer venting. Therefore, HYSPLIT simulations of tracers released within the boundary layer resulted in higher simulated surface concentrations with the STILT scheme than the HYSPLIT dispersion scheme. The extreme convection scheme can simulate significantly more convective mixing than reality. However, it is important to note that the extreme convection scheme is not meant to be used alone, but to be used alongside a simulation with convection turned off to bound dispersion results due to convection. The WRF vertical interpolation scheme, Hanna vertical Lagrangian time scale, Hanna turbulence parameterization, STILT module for estimating boundary layer height, and Grell convection scheme were not found to be consistently statistically different than other options available in HYSPLIT. Additional work evaluating these schemes may result in determining ideal model configurations for different atmospheric conditions. Reversibility tests show that backward dispersion simulations have similar performance characteristics than forward dispersion simulations.

Acknowledgments. We are grateful to the NOAA OAR Climate Program Office, which partially funded this work (NA17OAR4310087 and NA17OAR4310084). This study was also partially supported by NOAA Grants NA14NES320003 [Cooperative Institute for Climate and Satellites (CICS)] and NA19NES4320003 [Cooperative Institute for Satellite Earth System Studies (CISESS)] at the University of Maryland Earth System Science Interdisciplinary Center (ESSIC). The support and resources from the Center for High Performance Computing at the University of Utah are gratefully acknowledged.

Data availability statement. HYSPLIT meteorological input files derived from a $27-\mathrm{km}$ WRF simulation are publicly available and archived on the NOAA ARL ftp site (ftp:// arlftp.arlhq.noaa.gov/archives/wrf27km/). CAPTEX measurement data used to evaluate HYSPLIT simulations are publicly available on the NOAA ARL website (https:// www.arl.noaa.gov/wp_arl/wp-content/uploads/documents/datem/ exp_data/captex/).

\section{REFERENCES}

Draxler, R. R., 2003: Evaluation of an ensemble dispersion calculation. J. Appl. Meteor., 42, 308-317, https://doi.org/10.1175/ 1520-0450(2003)042<0308:EOAEDC > 2.0.CO;2.

_ 2006: The use of global and mesoscale meteorological model data to predict the transport and dispersion of tracer plumes over Washington, D.C. Wea. Forecasting, 21, 383-394, https:// doi.org/10.1175/WAF926.1.

—_, and J. L. Heffter, Eds., 1989: Description, ground-level sampling at primary sites, and meteorology. Vol. I, Across North America Tracer Experiment (ANATEX), NOAA Tech. Memo. ERL ARL-167, 83 pp., https://www.arl.noaa.gov/ documents/reports/arl-167.pdf.

— eling system. NOAA Tech. Memo. ERL ARL-224, 31 pp., https://www.arl.noaa.gov/documents/reports/arl-224.pdf.

_ and — 1998: An overview of the HYSPLIT_4 modeling system for trajectories, dispersion, and deposition. Aust. Meteor. Mag., 47, 295-308.

Fasoli, B., J. C. Lin, D. R. Bowling, L. Mitchell, and D. Mendoza, 2018: Simulating atmospheric tracer concentrations for spatially distributed receptors: Updates to the Stochastic TimeInverted Lagrangian Transport model's R interface (STILT-R version 2). Geosci. Model Dev., 11, 2813-2824, https://doi.org/ 10.5194/gmd-11-2813-2018.

Ferber, G. J., J. L. Heffter, R. R. Draxler, R. J. Lagomarsino, F. L. Thomas, and R. N. Dietz, 1986: Cross-Appalachian Tracer Experiment (CAPTEX-83) final report. NOAA Tech. Memo. ERL ARL-142, 60 pp., https://www.arl.noaa.gov/documents/ reports/arl-142.pdf.

Forster, C., A. Stohl, and P. Seibert, 2007: Parameterization of convective transport in a Lagrangian particle dispersion model and its evaluation. J. Appl. Meteor. Climatol., 46, 403-422, https://doi.org/10.1175/JAM2470.1.

Gerbig, C., J. C. Lin, S. C. Wofsy, B. C. Daube, A. E. Andrews, B. B. Stephens, P. S. Bakwin, and C. A. Grainger, 2003: Toward constraining regional-scale fluxes of $\mathrm{CO}_{2}$ with atmospheric observations over a continent: 2 . Analysis of COBRA data using a receptor-oriented framework. J. Geophys. Res., 108, 4757, https://doi.org/10.1029/2003JD003770. 
Göckede, M., A. M. Michalak, D. Vickers, D. P. Turner, and B. E. Law, 2010: Atmospheric inverse modeling to constrain regional scale $\mathrm{CO}_{2}$ budgets at high spatial and temporal resolution. J. Geophys. Res., 115, D15113, https://doi.org/10.1029/ 2009JD012257.

Grell, G. A., and D. Devenyi, 2002: A generalized approach to parameterizing convection combining ensemble and data assimilation techniques. Geophys. Res. Lett., 29, 1693, https:// doi.org/10.1029/2002GL015311.

—_ J. Dudhia, and D. R. Stauffer, 1994: A description of the fifth generation Penn State/NCAR mesoscale model (MM5). NCAR Tech Note NCAR/TN-398+STR, 121 pp., https:// doi.org/10.5065/D60Z716B.

Hanna, S. R., 1982: Applications in air pollution modeling. Atmospheric Turbulence and Air Pollution Modelling, F. T. M. Nieuwstadt and H. Van Dop, Eds., D. Reidel, 275-310.

Hegarty, J., and Coauthors, 2013: Evaluation of Lagrangian particle dispersion models with measurements from controlled tracer releases. J. Appl. Meteor. Climatol., 52, 2623-2637, https://doi.org/10.1175/JAMC-D-13-0125.1.

Holtslag, A. A. M., and B. A. Boville, 1993: Local versus nonlocal boundary-layer diffusion in a global climate model. J. Climate, $\mathbf{6}$, 1825-1842, https://doi.org/10.1175/1520-0442(1993)006<1825: LVNBLD $>2.0 . \mathrm{CO} ; 2$.

Lei, L., D. R. Stauffer, and A. Deng, 2012: A hybrid nudgingensemble Kalman filter approach to data assimilation in WRF/ DART. Quart. J. Roy. Meteor. Soc., 138, 2066-2078, https:// doi.org/10.1002/qj.1939.

Lin, J. C., and C. Gerbig, 2012: How can we satisfy the well-mixed criterion in highly inhomogeneous flows? A practical approach. Lagrangian Modeling of the Atmosphere, Geophys. Monogr., Vol. 200, Amer. Geophys. Union, 59-69, https:// doi.org/10.1029/2012GM001232.

_- - - - S. C. Wofsy, B. C. Daube, A. E. Andrews, K. J. Davis, and C. A. Grainger, 2003: A near-field tool for simulating the upstream influence of atmospheric observations: The Stochastic Time-Inverted Lagrangian Transport (STILT) model. J. Geophys. Res., 108, 4493, https://doi.org/ 10.1029/2002JD003161.

—, D. V. Mallia, D. Wu, and B. B. Stephens, 2017: How can mountaintop $\mathrm{CO}_{2}$ observations be used to constrain regional carbon fluxes? Atmos. Chem. Phys., 17, 5561-5581, https:// doi.org/10.5194/acp-17-5561-2017.

McKain, K., S. C. Wofsy, T. Nehrkorn, J. Eluszkiewicz, J. R. Ehleringer, and B. B. Stephens, 2012: Assessment of groundbased atmospheric observations for verification of greenhouse gas emissions from an urban region. Proc. Natl. Acad. Sci. USA, 109, 8423-8428, https://doi.org/10.1073/pnas.1116645109.
Miller, S. M., and Coauthors, 2013: Anthropogenic emissions of methane in the United States. Proc. Natl. Acad. Sci. USA, 110, 20 018-20 022, https://doi.org/10.1073/pnas.1314392110.

Nehrkorn, T., J. Eluszkiewicz, S. C. Wofsy, J. C. Lin, C. Gerbig, M. Longo, and S. Freitas, 2010: Coupled Weather Research and Forecasting-Stochastic Time-Inverted Lagrangian Transport (WRF-STILT) model. Meteor. Atmos. Phys., 107, 51-64, https://doi.org/10.1007/s00703-010-0068-x.

Ngan, F., and A. F. Stein, 2017: A long-term WRF meteorological archive for dispersion simulations: Application to controlled tracer experiments. J. Appl. Meteor. Climatol., 56, 2203-2220, https://doi.org/10.1175/JAMC-D-16-0345.1.

— A. Stein, and R. Draxler, 2015: Inline coupling of WRFHYSPLIT: Model development and evaluation using tracer experiments. J. Appl. Meteor. Climatol., 54, 1162-1176, https:// doi.org/10.1175/JAMC-D-14-0247.1.

— C. P. Loughner, and A. Stein, 2019: The evaluation of mixing methods in HYSPLIT using measurements from controlled tracer experiments. Atmos. Environ., 219, 117043, https:// doi.org/10.1016/j.atmosenv.2019.117043.

Peltier, L. J., S. E. Haupt, J. C. Wyngaard, D. R. Stauffer, A. Deng, J. A. Lee, K. J. Long, and A. J. Annunzio, 2010: Parameterizing mesoscale wind uncertainty for dispersion modeling. J. Appl. Meteor. Climatol., 49, 1604-1614, https://doi.org/10.1175/ 2010JAMC2396.1.

$\mathrm{R}$ Core Team, 2020: A language and environment for statistical computing. Accessed 29 June 2020, https://www.r-project.org.

Sargent, M. Y., and Coauthors, 2018: Anthropogenic and biogenic $\mathrm{CO}_{2}$ fluxes in the Boston urban region. Proc. Natl. Acad. Sci. USA, 115, 7491-7496, https://doi.org/10.1073/pnas.1803715115.

Skamarock, W. C., and Coauthors, 2008: A description of the Advanced Research WRF version 3. NCAR Tech Note NCAR/ TN-475+STR, 113 pp., https://doi.org/10.5065/D68S4MVH.

Stein, A. R., R. R. Draxler, G. D. Rolph, B. J. B. Stunder, and M. D. Cohen, 2015: NOAA's HYSPLIT atmospheric transport and dispersion modeling system. Bull. Amer. Meteor. Soc., 96, 2059-2077, https://doi.org/10.1175/BAMS-D-14-00110.1.

Stohl, A., M. Hittenberger, and G. Wotawa, 1998: Validation of the Lagrangian particle dispersion model FLEXPART against large-scale tracer experiment data. Atmos. Environ., 32, 42454264, https://doi.org/10.1016/S1352-2310(98)00184-8.

Thomson, D. J., W. L. Physick, and R. H. Maryon, 1997: Treatment of interfaces in random walk dispersion models. J. Appl. Meteor., 36, 1284-1295, https://doi.org/10.1175/15200450(1997)036<1284:TOIIRW >2.0.CO;2.

Vogelezang, D. H. P., and A. A. M. Holtslag, 1996: Evaluation and model impacts of alternative boundary-layer height formulations. Bound.-Layer Meteor., 81, 245-269, https://doi.org/ 10.1007/BF02430331. 